\title{
Natural and Sustainable Raw Materials for Sanitary Napkin
}

\section{Barman A*, Katkar PM and Asagekar SD}

Department of Textile, DKTE, Society's Textile and Engineering Institute Ichalkaranji, Maharashtra, India

\begin{abstract}
The present paper highlights the issue of non-biodegradability of personal hygiene product and how it has become a serious environmental concern all over the world. Emphasis is given to use naturally available absorbent fibres such as organic cotton, banana fibre, jute, bamboo etc., which are widely available and biodegradable in nature having low carbon footprint which not only makes it eco-friendly but also reduces the cost of sanitary pad. And to enhance the retention of fluid cellulose based hydro gel can be used instead of synthetic super absorbent polymer. Sustainability of hygiene product can be attained by replacing petroleum based raw material with an ecofriendly one.
\end{abstract}

Keywords: Biopolymer; Biodegradability; Natural fibre; Sustainable material

\section{Introduction}

Currently, the world is facing a very big problem of carbon footprint of feminine hygiene product. As there is a huge amount of non-biodegradable material dumped in landfill, which releases harmful gasses into to the atmosphere. India being a developing country, with a population of 1.34 billion, out of which 323.6 million female between the age group of 15-49 [1]. If we consider that $10 \%$ of Indian women uses disposable sanitary pad then each individual will generate at least half a kilo of waste a month. In that way, $10 \%$ of the female population in India will generate 16180 tons of waste every month. In order to deal with it, we need to focus on developing a more sustainable product by choosing the raw material having low carbon footprint. Material which are used in feminine hygiene product are derived from natural resource mostly petroleum based which cannot be reused or compost and at the same time over-exploitation of these resources have to be stopped otherwise nothing will be left for our future generation. We have to find an alternative raw material that is sustainable in nature, without compromising on the functional requirement of the product [2].

\section{Conventional structure and material used in sanitary napkin}

In order to classify the raw material for sanitary pad, first we have to understand the basic mechanism how a sanitary pad works, what are their requirements and accordingly we have to select the same. Sanitary pad comprises of multilayered structure in which each layer have specific function to perform. It consists of three main layers the top sheet, absorbent core and barrier sheet (Figure 1).

a) Top sheet: It is designed to transfer fluid quickly from the top sheet to secondary layers. The top sheet contains thermoplastic fibers to prevent capillary collapse of this layer, and small amount of hydrophilic absorbent fibre to allow fluid to absorb. Commercially available top

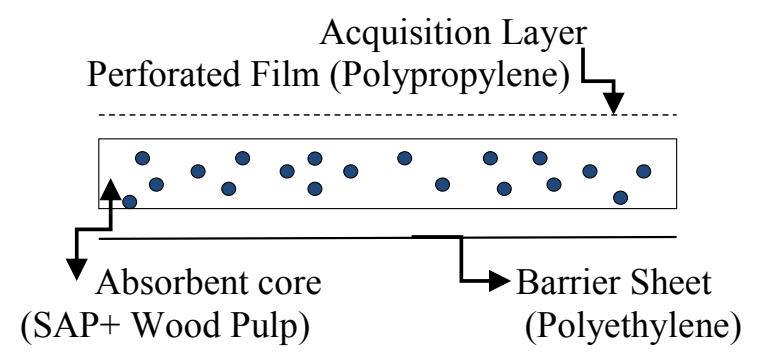

Figure 1: Conventional structure and material used in sanitary napkin. sheet are made up of polypropylene fibre [3].

b) Absorbent core: It is interposed between top sheet and barrier layer main function is to absorb and retain the fluid. Moreover, to have comfort, absorbent core need to be thin, soft and pliable. The core was made up of wood pulp traditionally but there is constant effort to replace it by air laid wood pulp and SAP to improve its absorption efficiency. SAP turns the absorbed liquid into a jelly-like state so that it would not retract back $[4,5]$.

c) Barrier sheet: It seals the fluid from staining or leakages. It is a breathable but fluid impermeable film made up of polyethylene [6].

Few components of sanitary pad will disintegrate and be attacked by the bacteria in a public or private sewage disposal system but polyethylene or polymeric films used as a barrier sheet remain intact as this polymer are inert and are not broken down by bacteria and thus pollutes the environment.

\section{Alternative sustainable raw material to disposable hygiene product}

The following raw materials can be used to replace existing material used in sanitary pads.

Raw material for top sheet: Organic cotton as top sheet is one the commonly advised raw material for sanitary napkin because of its non-irritant, skin friendly and superior liquid retention properties. It is soft and breathable which gives comfort and dryness. Cotton wicks away moisture and keeps skin dry and its $\mathrm{pH}$ compatibility makes it skin friendly $[7,8]$. Organic cotton are cultivated from non-treated Genetically Modified (GMO) seed and is grown using method and materials having low impact on environment that is without any use of synthetic agricultural chemical such as fertilizer and pesticides. The crop needs to be certified by a certifying body or the USDA. As cotton fibre comes directly from nature, it degrade when disposed [9].

*Corresponding author: Barman A, Research Scholar, Department of Textile, DKTE, Society's Textile and Engineering Institute Ichalkaranji-416115, Maharashtra, India; Tel: 0230242 1300; E-mail: anuradha.barman00@gmail.com

Received June 30, 2017; Accepted July 13, 2017; Published July 20, 2017

Citation: Barman A, Katkar PM, Asagekar SD (2017) Natural and Sustainable Raw Materials for Sanitary Napkin. J Textile Sci Eng 7: 308. doi: 10.4172/21658064.1000308

Copyright: @ 2017 Barman A, et al. This is an open-access article distributed under the terms of the Creative Commons Attribution License, which permits unrestricted use, distribution, and reproduction in any medium, provided the original author and source are credited. 
Recently Lenzing have come up with a new fibre called TENCEL'Biosoft which is a lyocell fibre, fully biodegradable and hydrophobic in nature with extra softness that makes it an excellent choice to be used as top sheet. Tencel is incredibly comfortable because of its even surface and has excellent moisture transfusion through capillary action and wicking [10]. It has a distinctive fibril configuration; fibrils are like fine hair like structure. The submicroscopic channel between the individual fibrils control absorption and liberate moisture. Thus, these tiny fibrils assure best possible transportation of moisture. The ideal moisture management of this cellulosic fiber is responsible for the reduced bacteria growth [11].

Raw material for absorbent core: The primary requirement of sanitary pad is absorbency of menstrual fluid. Therefore, selection of core material totally depends on the absorbency and retention property of fibre. Bamboo fibre is a novel alternative raw material for absorbent core. Bamboo absorbs and wicks water 3-4 times better than cotton and reduces odor as the fiber is filled with multiple micro-holes and micro-gaps. Bamboo is soft to feel as the fibre is naturally round in shape it does not require any chemical treatment to smoothen it. An additional significant property of bamboo is the anti-microbial agent that is bamboo kun naturally present in it $[9,12]$. In one of the research work done by IIT Kharagpur, Jute fibre was used to substitute cotton pad. And it was found that jute fibre is one of the best replacements for cotton as healthy production of jute in eastern India facilitates this fiber with $65-70 \%$ cellulose content and high water affinity. Jute is having lower price than cotton fibre and abundant in north-east of India. The additional advantage of jute fibers to cotton is that the fiber length is much shorter in the case of jute easing the preparation of cellulose pulp $[13,14]$.

Sanitary pads from banana fibre were developed by SHE (Sustainable Health Enterprises) a non-profitable NGO, their intention was to make affordable, quality and eco-friendly sanitary napkins available to girls and women in developing country. Banana is a natural absorbent fibre; the key reason is its natural porosity. Banana fibre is an eco-friendly fibre like jute fibre. It is bio-degradable and has no negative effect on environment and thus can be categorized as eco-friendly fibre. Banana fibre is mainly cultivated for fruit. The fibres are harvested from the plant's trunk, which are normally unused and go to waste $[15,16]$.

Studies have been done to replace cotton fillers by flax spinning waste to be used as an absorbent core of sanitary pad, which is much cheaper than pure cotton as well as highly absorbent and have natural cellulosic composition. It was observed that absorbency of fibre increased after scouring and bleaching. To give antimicrobial activity flax absorbent core was treated with $70 \%$ aloegel extract which showed satisfactory antimicrobial and antifungal potential [17].

To further improve the absorbency of sanitary pad cellulose based hydrogel were manufactured to imitate synthetic superabsorbent polymer by a sustainable process using a nontoxic cross linking agent. Cellulose based hydro gel are based on sodium carboxy methylcellulose (NaCMC) and hydroxyethyl cellulose (HEC) cross linked with divinylsulfone (DVS). It can swell like SAP and shows fluid retention under centrifugal load. These has been possible by introducing microporous structure into the hydrogel ,by introducing phase inversion desiccation technique in acetone, which increases the retention and swelling kinetics due to capillary effect. Main advantage of cellulose-based hydrogel over current SAP is that they are environment friendly, biodegradable and excellent biocompatibility $[18,19]$.

\section{Raw material for barrier sheet}

Widely used protective film in hygiene products are polyethylene and polyurethane, which are non-biodegradable plastic. This plastic material can be replaced by bio-based plastic prepared from starch. Many research works on bio-plastic are in progress. Biodegradable plastic can be a bio-derived and biodegradable/compostable (e.g., polylactides, polyhydroxyalkanoates) or a fossil fuel-derived and biodegradable (e.g., polycaprolactone) [20]. Nonabsorbent fibres such as polypropylene, ethylene etc. are derived from petroleum resources, which have high carbon footprint and non-biodegradable in nature. An alternative sustainable replacement of petroleum- based fibre is the PLA (Poly Lactic Acid) fibre, which is derived from cornstarch using latest biotechnology. It is most promising thermoplastic biodegradable polymer material. In order to enhance the functional property of PLA, $\mathrm{TiO} 2 / \mathrm{Ag}+$ is added which give an antimicrobial property to PLA. After adding a copy of inorganic nano- $\mathrm{TiO} 2 / \mathrm{Ag}+$, the antibacterial rate of PLA films to Coli bacillus, Staphylococcus and Mildew were exceeded 95\% [21]. Non-toxic, anti-bacterial and biodegradable characteristic of modified PLA makes it an excellent choice to be used in hygiene industry. The only drawback at present is the high cost of synthesis of this high molecular weight PLA that is 5-6 times more than conventional plastic [22].

\section{Conclusion}

Nature has encompassed every solution within itself. With more and more use of natural fibre in hygiene product will make it ecofriendly. Use of natural fibre in sanitary pad will reduce the cost of the product will lower accessible to low income group women. As the product is biodegradable, prevent non-biodegradable waste generation. We as a technologist have to find a sustainable way so that we endow a better world for next generation.

\section{References}

1. World population review (2017) World population by country.

2. Farage MA (2007) A Behind the scenes look at the safety assessment of feminine hygiene pads, The NewYork academy of sciences.

3. Teli MD, Mallick A, Srivastava A (2015) Parameters of choice of sanitary napkins-a techno-commercial survey. Journal of the Textile Association 76: 235-235.

4. Woeller KE, Hochwalt KE (2015) Safety assessment of sanitary pads with a polymeric foam absorbent core. Regulatory Toxicology and Pharmacology 73 : 419-424.

5. Gupta BS (1992) Study of absorbency in Non Woven: The role of structure factors and fluid characteristic. Papers of International Conference on Non Woven, Published in 1992 The Textile Institute North India Section.

6. Shishoo RL (1992) Analysis of structure- absorbency relationship in disposable hygienic products. Papers of International Conference on non wovens, The Textile Institute North India Section.

7. Pohlmann M (2016) Design and materials selection: analysis of similar sanitary pads for daily use. International Journal of Engineering Research and Application 6: 74-79.

8. Pepper LR, Dumain J (2016) Textile exchange organic cotton market report.

9. Shanmugasundaram OL, Gowda RVM (2010) Development and characterization of bamboo and organic cotton blended baby diapers. Indian Journal of Fiber \&Textile Research 35: 201-205.

10. Schachtner B, Maier A (2013) TENCEL ${ }^{\circledR}$ biosoft-a complete new fibre development: soft-hydrophobic-botanic. Lenzinger Berichte 91: 53-55.

11. Dhinakaran M, Senthil CS, Sathis TK (2017) Development and characterization of sanitary napkins with Lyocell/Modal as absorbent core. International Research Journal of Engineering and Technology 4: 1003-1006. 
Citation: Barman A, Katkar PM, Asagekar SD (2017) Natural and Sustainable Raw Materials for Sanitary Napkin. J Textile Sci Eng 7: 308. doi: 10.4172/2165-8064.1000308

Page 3 of 3

12. Mburu A, Kinyanjui J (2013) Development of a highly adsorbemt and antibacterial biodegradable sanitary pad from bamboo. International Conference National Council for Science and Technology $2^{\text {nd }}$ National Science 4.

13. Chattopadhayay SN, Ghosh RK, Bhattacharyya S, Bhowmick S (2012) Development of eco-Friendly and sustainable feminine hygiene products from lignocellulosic jute fibre.

14. Project report (2013) Development of cotton lap/cellulose pad substitute from Jute by IIT Kharagpur.

15. Brindha MD, Vinodhini V, Alarmelumangai K, Malathy NS (2012) Physicochemical properties of fibres from banana varieties after scouring. Indian Journal of Fundamental and Applied Life Sciences 2: 217-221.

16. She:Sustainable Health Enterprises (2008) The beginning of sustainable health enterprises.

17. Mishra S, Pandey R, Singh MK (2016) Development of sanitary napkin by flax carding waste as absorbent core with herbal and antimicrobial efficiency. International Journal of Science, Environment and Technology 5: 404-411.

18. Sannino A, Demitri C, Madaghiele M (2009) Biodegradable cellulose-based hydrogels: design and application. Materials 2: 353-357.

19. Hubbe MA, Ayoub A, Daystar JS, Venditti JS, Pawlak JJ, et al. (2013) Enhance absorbent products incorporating cellulose and its derivatives: A Review BioResource 8: 6556-6629.

20. Xiu, Wang J, Jin Z (2010) Preparation and Properties of Functionalization for PLA Film. Scientific Research, World Conference on Packing.

21. Olivato JB, Demiate IM, Müller CMO, Grossmann MVE (2016) Poly(Lactic Acid)/thermoplastic starch sheets: effect of adipate esters on the morphological, mechanical and barrier properties. Polimeros 26: 1678-5169.

22. Johansson C, Bras J, Mondragon I, Nechita P, Plackett D, et al. (2012) Renewable fibers and bio-based materials for packing applications-a review of recent developments. BioResources 7: 2506-2552. 